\title{
Brain cortical organization in entrepreneurs during a visual Stroop decision task
}

\author{
This article was published in the following Dove Press journal: \\ Neuroscience and Neuroeconomics \\ 8 November 2013 \\ Number of times this article has been viewed
}

\section{Elena Ortiz-Terán ${ }^{1,4}$ \\ Agustín Turrero \\ Juan M Santos ${ }^{3}$ \\ Peter T Bryant ${ }^{1}$ \\ Tomás Ortiz ${ }^{4}$}

'IE Business School, ${ }^{2}$ Department of Statistics, Universidad Complutense, Madrid, Spain; ${ }^{3}$ Fundación J Robert

Cade and Department of Psychiatry, Universidad Católica de Córdoba, Córdoba, Argentina; ${ }^{4}$ Department of Psychiatry, Universidad Complutense, Madrid, Spain
Correspondence: Elena Ortiz-Terán Universidad Complutense De Madrid, Avenida Complutense S/N,

Facultad de Medicina, Departamento de Psiquiatría, 28040 Madrid, Spain

Email elenaortizteran@gmail.com
Abstract: Decision-making in entrepreneurs is a key aspect of their skills, but much about these processes remains unexplained. During a Stroop task, concomitant N200, P300, and N450 eventrelated potentials were measured in 25 founder entrepreneurs and in age-matched and gendermatched nonfounders/nonentrepreneurs (NFNE). Reaction times were shorter among founder entrepreneurs. The N200 was shorter and N450 larger in founder entrepreneurs. The personalities of both groups were measured using the Temperament and Character Inventory-Revised. Founder entrepreneurs scored significantly higher in novelty-seeking and self-directedness dimensions, as well as in exploratory excitability, impulsiveness, optimism, eagerness, and responsibility subdimensions. Possible interactions among candidate variables to differentiate between founder entrepreneurs versus NFNE were also addressed, and the model including impulsivity, N450 latency, and impulsivity*N450 interaction came up as the best model for discrimination between founder entrepreneurs and NFNE. A shorter N200, mostly associated with bilateral supplementary motor area activation, revealed a faster capability to make decisions when information was noncongruent or blurred. However, the larger N450 revealed a more intense post-evaluation cognitive process happening in founder entrepreneurs and was accompanied by a greater activation of anterior frontal regions. The whole decision-making process consumed more time and resources in founder entrepreneurs, even if its closure was faster. Attention, memory, and alertness, among other factors, have been invoked to explain some of these differences. Founder entrepreneurs may have cognitive and heuristic differences compared with the general population.

Keywords: entrepreneur, founder, Stroop, N200, P300, N450, personality, Temperament and Character Inventory-Revised, decision-making

\section{Introduction}

Decision-making is a common task, even inadvertently, but for entrepreneurs this is a key issue. ${ }^{1}$ Among the many decisions entrepreneurs are confronted with, they must decide about which opportunities to pursue, how to obtain resources, with whom to work, and how to resolve the many risks and uncertainties of creating a new venture. Hence, entrepreneurial decision-making consists of multiple operations, including option evaluation, actions, and outcome monitoring. ${ }^{2}$ Entrepreneurial decision-making plays a pivotal role in translating perception into action ${ }^{3}$ and is affected by factors such as personality or attention, among others. ${ }^{4}$ Therefore, numerous studies have investigated the psychologic foundations of decision-making among entrepreneurs, hoping to explain better how some people acquire stronger capabilities or why some may be more inherently adept at decision-making in this field. ${ }^{5}$ Our research builds 
upon this literature by studying the relationship between key neurophysiologic and personality characteristics in entrepreneurial decision-making.

A comprehensive neuroanatomic model for decisionmaking remains far from being fully elucidated, but there is a growing consensus that premotor frontal and parietal regions are involved. Decision-making includes several cognitive processing steps, ie, preparation for certain stimuli, evaluation of the validity (or invalidity) of the preparatory state, and feedback cycling of the information extracted from one trial to the next. In daily life, humans monitor their actions in a constant fashion to ensure that their responses are environmentally appropriate. This requires the interaction of sensory and executive networks at different levels of the processing hierarchy, ${ }^{6}$ which leads to the final step of decision-making, ie, execution of a motor response. ${ }^{7}$

Event-related potentials (ERPs) are valid markers of neuronal activation accompanying task performance. Their topography and amplitude are strongly task-dependent. The amplitude of ERPs varies with the amount of neuronal activation $^{8}$ and the amount of mental effort. ${ }^{9,10}$ ERP topography varies with the underlying cognitive process ${ }^{11-13}$ and is correlated with the brain location of the underlying neural generators. ${ }^{14}$

ERP components, such as the N200, P300, and N450, have complex sensitivities related to task parameters. They reflect higher order cognitive processes, eg, selection and working memory.

The N200 is associated with changing features in the stimulus environment and has been interpreted as an automatic filtering stage for selective attention towards novelty. ${ }^{15}$ Two specific cognitive processes (response selection and executive control), both related to response inhibition, have been identified in the N200. ${ }^{16,17}$ Dysfunctions in response inhibition have been linked to alterations in impulse control and reduced N200 in different frontal and central regions. ${ }^{18}$

The P300 is a positive waveform occurring approximately $300 \mathrm{msec}$ after stimulus onset and is associated with both working memory and attention. ${ }^{19-23}$ The P300 is generated within multiple structures, including the parietal, temporal, and frontal cortices. ${ }^{24,25}$ A post-decisional "cognitive closure" mechanism has been related to the $\mathrm{P} 300 .{ }^{26} \mathrm{~A}$ similar statement can be made about the $\mathrm{P} 300$ and accessing consciousness. ${ }^{27}$ The P300 can serve as a marker of working memory in evaluation of environmental stimuli whenever an ongoing task requires identification of salient information. ${ }^{20}$

The more negative ERP components around $400 \mathrm{msec}$ are associated with completion of cognitive processing.
This late negative ERP component could reflect the process of retrieving images from memory. It has been reported in the frontal-central areas, left superior/middle temporal gyrus, anterior-medial temporal lobe, parahippocampal cortex, and anterior fusiform gyrus, during mental rehearsal imagery tasks. ${ }^{23,28,29}$ The N450 may be related to a distributed and multimodal system that responds to both verbal and nonverbal stimuli. ${ }^{30}$

Cognitive tasks that require detection of processing conflicts between competing response options (eg, incongruent condition of the Stroop task) reliably elicit a N450. ${ }^{31-38}$ The N450 is present following both stimulus and response conflict. ${ }^{39,40}$

According to the conflict monitoring view, ${ }^{41-43}$ activity of the anterior cingulate cortex is directly proportional to the degree of conflicting information. It has been shown that both the posterior parietal cortex $\mathrm{x}^{44,45}$ and the inferior parietal cortex ${ }^{46}$ may be related to conflictive information processing. Similarly, response conflict has been reported to modulate premotor cortex activity, ${ }^{45}$ as well as that in the dorsolateral prefrontal cortex. ${ }^{47}$ ERP studies on interference effects during the Stroop task have shown greater negativity from frontal-central to central parietal regions around $450 \mathrm{msec}$ to incongruent stimuli after stimulus presentation. . $^{31,35,48}$

Founder entrepreneurs, defined here as persons who have founded a new venture in order to exploit opportunities, are sometimes assumed to be more heterogeneous than the rest of the population ${ }^{49}$ and those who have never founded new ventures and those with no entrepreneurial background (NFNE). Suffice it to say their differences in decision-making, why the former can transform an event into an opportunity, and the extent to which entrepreneurs can detect environmental differences better, even leading them to create and erect a company, are relevant issues that are not sufficiently understood. Some authors have even spoken of "entrepreneurial cognition", defined as "knowledge structures that people use to make assessments, judgments or decisions involving opportunity evaluation, venture creation and growth." ${ }^{50}$

A considerable amount of research has been done based on the premise that company founders and entrepreneurs have a cognitive style that is different to that of business executives or the general population. ${ }^{51}$ Significant evidence supports this view, ${ }^{4}$ although it remains a topic of debate. ${ }^{52}$ Nevertheless, there is a huge gap in the research about neurobiologic parameters related to decision-making which may differ between entrepreneurs and nonentrepreneurs. Moreover, the integration of neurobiological variables with personality within this context has not been previously addressed. 
Our hypothesis is that decision-making is different, both neurophysiologically and in terms of reaction time, in founder entrepreneurs when compared with NFNE. In order to address this issue, we compared a founder entrepreneur group and an NFNE group during a Stroop task, and measured some specific concomitant ERPs and their respective brain locations, as well as their behavioral responses. We also took into account personality differences between the two groups.

\section{Materials and methods Participants}

Twenty-five founder entrepreneurs comprising 20 men and five women of mean age $33.36 \pm 5.67$ years (group 1 , experimental or case group) were recruited from several firms after initial contact via telephone. Our operational definition of a founder entrepreneur was anyone who had created at least one company and had been or was either the current executive director or holder of a directorial position at the time of our study. Twenty-five NFNE, defined as people who have never created a company and were not in training to start a company, were also recruited. This group was matched for gender, age, and academic achievement, and comprised 20 men and five women of mean age $31.48 \pm 6.34$ years (group 2, controls). Thus, our data set consisted of 50 casecontrol pairs matched for gender, age, and education level. Two participants reported being left-handed (one from each group). The rest were all right-handed. Nobody reported being color-blind.

Recruitment was carried out at the IE Business School in Madrid, Spain. We started with a list of former graduates from this institution and another list of founder entrepreneurs from the Madrid region associated with the IE in some capacity. An initial random selection took place. Once identified, potential participants were contacted via telephone by the researchers and the nature and purpose of the study was explained to them. They were offered a personal interview and ample opportunity to ask as many questions about the experiment as they wanted. Thirteen of $38(34 \%)$ potential subjects contacted refused to participate. The age and gender distribution of those who refused to enter into the study was similar to that in the experimental group, but no other data were gathered from those who refused to participate. Recruitment continued until 25 people were selected.

The control group was recruited from undergraduate and postgraduate students at universities and business schools in Madrid, using available open lists. Once an individual from the experimental group (founder entrepreneurs) had been selected, a gender-matched NFNE control of similar age was chosen at random. Potential controls were also contacted by telephone, a personal interview was offered, and the nature and purpose of the study was explained. All were given the opportunity to ask any questions they wanted. The refusal rate was $43 \%$ (19 of 44 ).

No one received any economic compensation for his/her participation in this research. All participants gave their written informed consent. The study was approved by the IE Business School ethical committee and adhered to the principles stated by the Declaration of Helsinki.

\section{Temperament and Character Inventory-Revised}

Cloninger designed a tool for evaluation of different dimensions defined in his psychobiological model of personality, ie, the Temperament and Character Inventory-Revised (TCI-R). ${ }^{53}$ We focused our attention on the following dimensions and subdimensions: novelty-seeking (exploratory excitability, impulsiveness, extravagance, disorderliness), harm avoidance (optimism, fear of uncertain, shyness with strangers, fatigability), reward-dependence (sentimentality, openness to warm communication, attachment, dependence), persistence (eagerness, work-hardened, ambitious, perfectionist), and self-directedness (responsibility, purposefulness, resourcefulness, self-acceptance, congruent habits). ${ }^{53}$

\section{Stimuli}

The basic Stroop reaction time task consisted of words about a variety of colors (blue, green, red) printed in colors different from that of the word itself (eg, the word "blue" printed in green or red) on a computer screen. Congruent stimuli (eg, the word "blue" printed in blue) were not used. Words with incongruent colors were displayed against a black background. The six stimuli (three words and three colors, always in incongruent fashion) were presented in a pseudorandom order, with targets occurring $75 \%$ of the time (100 word stimuli and 100 color stimuli). Distractors constituted $25 \%$ (70 stimuli) of the total number of stimuli. The target of this experiment was the color blue. In other words, only the color blue was used for analysis while the word "blue" was disregarded for this purpose.

Each word was presented for $300 \mathrm{msec}$ and was followed by a black pause of $700 \mathrm{msec}$, while participants were requested to provide an answer whenever either the word "blue" or the color blue appeared (Figure 1). The Stroop protocol lasted 4.5 minutes. The whole duration of the experiment was about 2 hours, including preparation of 


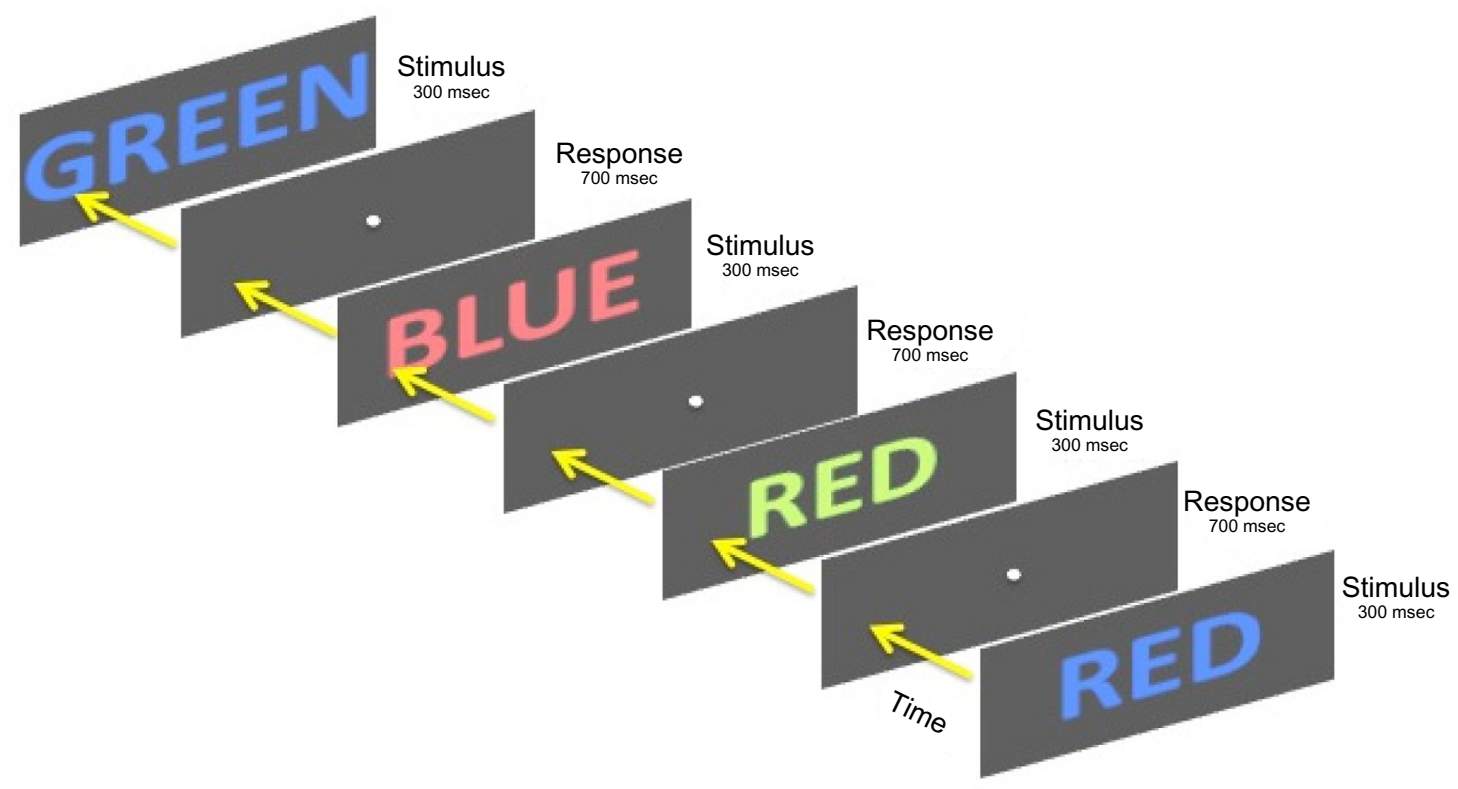

Figure I Diagrammatic representation of the Stroop experimental paradigm.

the electroencephalography (EEG) system, the Stroop task, and the TCI-R test.

\section{Procedure}

Electroencephalography testing, aimed at registering N200, P300 and N450 ERPs, was carried out. For this purpose, participants were tested on an individual basis in a small dimly lit room. They were comfortably seated in front of a 19-inch computer screen (refresh rate $100 \mathrm{~Hz}$ ), positioned $1 \mathrm{~m}$ from their eyes. They rested both hands on a standard Spanish keyboard connected to the computer screen. The participants were instructed to stay awake, keep their eyes open, blink as little as possible, and avoid abrupt movements. They were instructed to respond exclusively to the blue stimulus, regardless of whether it was the word "blue" or the color blue for words "green" and "red". The participants were asked to press the "Z" key with their left index finger whenever the word "blue" appeared and to press the "M" key with their right index finger for whichever word was colored in blue.

\section{Electrophysiologic testing}

High-density EEG recordings were made using a customdesigned 128-channel electrode Neuroscan cap with an ATIPentatek ${ }^{\circledR}$ EEG system (PentaTek, Buenos Aires, Argentina). A filter bandpass of $0.05-30 \mathrm{~Hz}$ and a sample rate of $512 \mathrm{~Hz}$ were used. Impedances were kept under $5 \mathrm{k} \Omega$. We used electrodes in both mastoids as on-line references. Data were referenced to an average standard following acquisition. An artifact rejection criterion of $100 \mathrm{mV}$ was used to exclude eye blinks.
From the remaining artifact-free trials, averages were computed for each participant and each condition, with a mean of $80 \%$ trials per average. Analysis was carried out using 1,000 msec epochs. Individual subject averages were visually inspected to ensure that clean recordings were obtained and no artefacts were included. Baseline was considered to be the voltage recorded at the beginning of the stimuli, or more specifically, as the average voltage at stimulus onset. Noisy channels were replaced with linear interpolations from clean channels sparingly.

Eye and muscle movement artifacts were identified off-line on a trial-by-trial basis through visual inspection and removed prior to data averaging and ERP analysis. The ERPs obtained were averaged separately for right hand color response and each subject. We analyzed the N200, P300, and N450 latencies from the highest peak amplitude of the $\mathrm{Pz}$ electrode. Source localization (low-resolution electromagnetic tomography [LORETA $]^{54,55}$ ) was done using the N200 (150-250 msec time window) and N450 (400-600 msec time window). The time taken to analyze the N200-P300-N450 components was determined by searching for the maximal amplitude in the respective time window at the Pz electrode. The LORETA analysis was done opening a time window of -20 to $+20 \mathrm{msec}$ starting from the highest amplitude peak measured in the Pz electrode. ${ }^{56} \mathrm{~A}$ visual explanation of the neurophysiologic testing used is provided in Figure 2.

\section{Source localization}

LORETA from the Neuronic ${ }^{\circledR}$ Source Localizer software was carried out in each individual ERP recording to identify 


\section{ERP waveforms}
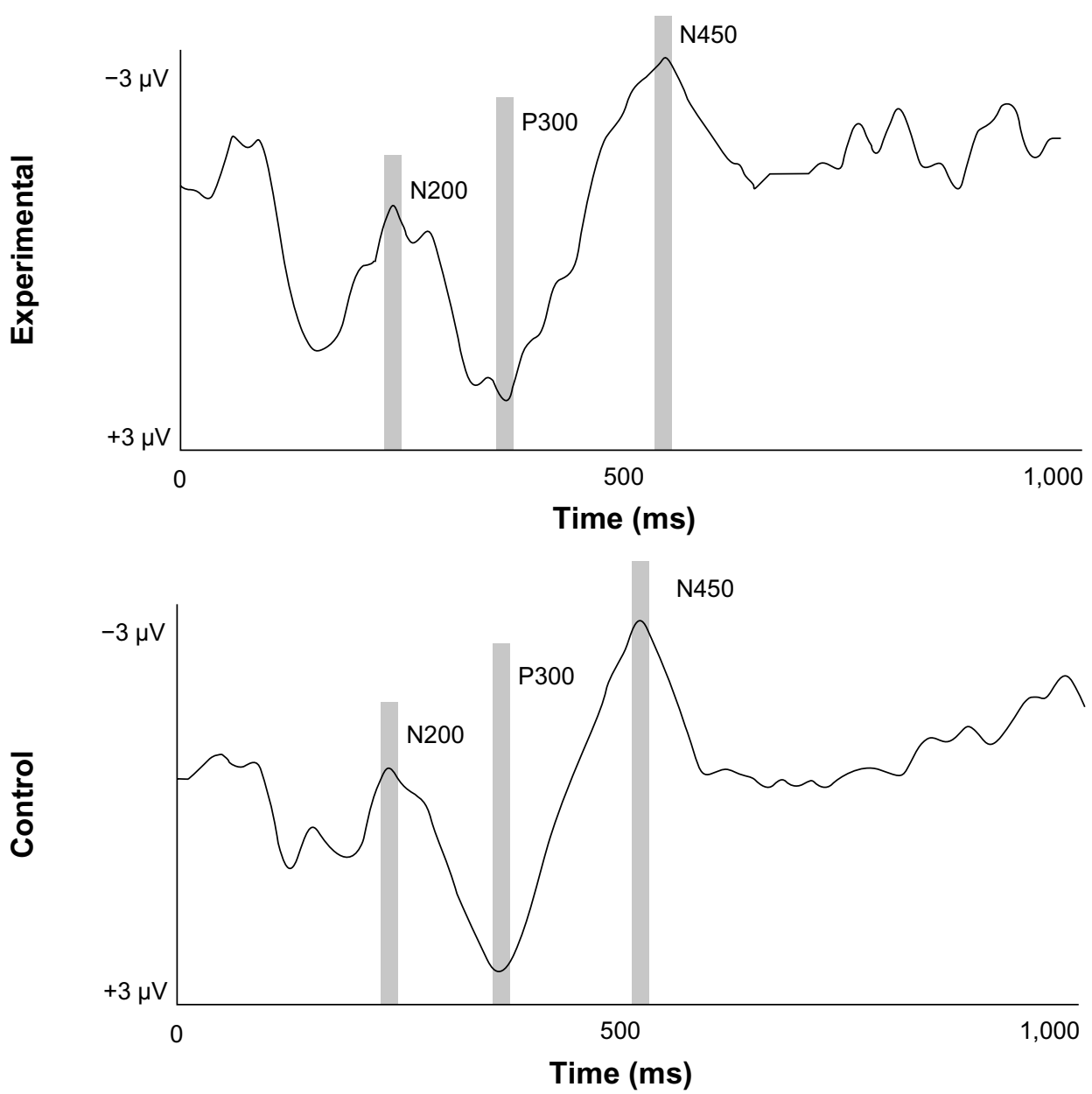

Figure 2 Grand average of ERPs in both groups for N200, P300, and N450 during the Stroop task. ERP components are shown from the Pz scalp location. The time frames for analysis of the N200, P300, and N450 components were determined by searching for the maximal amplitude in the respective time window at the Pz electrode. The LORETA analysis was made opening a time window of -20 to +20 msec starting from the highest amplitude peak measured in Pz electrode (interval \pm 20 msec for each of the ERPs considered is marked in gray).

Abbreviations: ERPs, event-related potentials; LORETA, low-resolution electromagnetic tomography.

underlying brain electric sources of the scalp potentials. ${ }^{54,55}$ This procedure computes the three dimensional distribution of the electrically active neuronal generators in the brain as a current density value $\left(\mathrm{A} / \mathrm{m}^{2}\right)$ at each voxel. The linear LORETA solution relies on a criterion of contiguity, ie, the activity at any given voxel in cortical gray matter must be as similar as possible to the average activity of neighboring voxels. This criterion draws on electrophysiologic evidence for the highly synchronized activity of neighboring neurons, necessary for generating the EEG. ${ }^{57}$ The source locations are therefore given as Montreal National Institute coordinates (" $x$ " from left to right, " $y$ " from posterior to anterior, " $z$ " from inferior to superior). Calculation of all reconstruction parameters is based on the computed common average reference. ${ }^{57}$

The LORETA method has been validated for face processing brain areas, as well as localization in other cortical regions. ${ }^{57}$ Different models have been defined by constraining the source to one anatomic compartment using the Probabilistic Brain Atlas (PBA) ${ }^{58,59}$ and Brodmann Atlas. For our purpose, a spatial resolution of $7 \mathrm{~mm}$ was used, rendering a three-dimensional LORETA image of 2,394 voxels in total for each scalp potential distribution map.

\section{Statistical analysis}

Two-sample $t$-tests were used to evaluate differences in personality (temperament and character) scores, reaction times, and latencies between the two groups. Nonparametric Mann-Whitney tests were used to compare ERP amplitudes. Pearson correlation coefficients were used to examine the relationship, in the whole sample, between significant personality scores on the one hand and significant latencies on the other. This correlation analysis suggests a reduction 
of scores and latencies when the analysis of the prognostic relevance of these measurements is undertaken, while discriminating between the groups (logistic regression analyses). The chi-square statistic was used to analyze the homogeneity of the groups with regard to the entrepreneurial nature of parents.

Linear regression models were used to analyze the effect of age on reaction times and significant latencies in the two groups. ANOVA $F$-tests were applied to study the effect of gender, considering gender and group as factors and both reaction times and latencies as dependent variables.

Finally, logistic regression analyses were used to select those variables useful for discriminating correctly between the experimental and control subjects. The independent (or predictor) variables initially considered were the significant temperament and character scores, reaction times, and significant latencies obtained in previous statistical analyses. The model's performance was assessed by means of classification tables, together with standard Hosmer-Lemeshow ${ }^{60}$ goodness of fit tests, and the Nagelkerke $R^{2}$ goodness of fit statistic. The efficiency of the final model was assessed by the area under the receiver-operating characteristic curve. All analyses were conducted using the Statistical Package for the Social Sciences version 19 software (IBM Corporation, Armonk, NY, USA).

A voxel-by-voxel EEG statistical mapping was computed to find mean differences in the activated cerebral sources between the groups. The independent Hotelling's 2 test for multiple comparisons between groups was used, considering the degrees of freedom and threshold values for $\alpha<0.01$ (corrected for multiple comparisons according to the contiguity of voxels criterion) for the N200, P300, and N450 epochs. ANOVA measurements, using the mean differences between the N200, P300, and N450 latencies, were used to compare each group. Analyses for the independent Hotelling's T-squared test were conducted using Neuronic ${ }^{\circledR}$ statistic software.

\section{Results}

\section{Differences in temperament and character measures between groups}

T-tests showed statistically significant differences only in the "novelty-seeking" dimension $(P=0.026)$. Analysis of subdimensions for five TCI-R dimensions showed statistically significant differences for "exploratory excitability" $(P=0.038)$, "impulsiveness" $(P<0.001)$, "eagerness" $(P=0.007)$, and "responsibility" $(P=0.049)$, with values generally larger in the founder entrepreneur group. Finally, "optimism" $(P=0.035)$ in the "harm avoidance" dimension showed significant differences, with values being generally lower in founder entrepreneurs. There was a close relationship between these five significant subdimensions. Thus, for the overall sample, all correlation coefficients, except for the "exploratory excitability"-“eagerness" and "responsibility""eagerness" correlations, were significant $(P<0.03)$. These findings suggest a potential variable reduction process when analysis of the prognostic importance of the TCI-R scores is undertaken (logistic regression analysis).

\section{Differences in reaction times and ERP latencies and amplitudes between groups}

In response to the target stimulus (color blue), the cerebralevoked potentials in both groups were associated with a negative wave (N200), followed by a positive wave (P300) and finally a negative wave (N450) complex. The amplitude, latency, and configuration of these components were similar for the cerebral responses to both groups (Figure 2).

The means and standard deviations of the reaction times and latencies for founder entrepreneurs and NFNE are shown in Table 1, which also shows the between-group differences in terms of Cohen's d effect sizes. ${ }^{61}$ The mean reaction time in controls was greater than that in the founder entrepreneur group. The $t$-test showed statistically significant differences $(P<0.05)$. The results for reaction time were homogeneous in both groups, with $97 \%$ being correct responses and $3 \%$ being errors.

Only the N200 and N450 latencies showed significant differences between the groups. In addition, observing Table 1 two numerical questions (issues) could be commented upon, ie, the control N200 and P300 latencies means were greater than those in the founder entrepreneurs, which is the

Table I Comparisons of reaction times and latencies (N200, P300, and N450) between founder entrepreneur and NFNE groups

\begin{tabular}{|c|c|c|c|c|}
\hline & RT & N200 & P300 & N450 \\
\hline \multicolumn{5}{|c|}{ Founder entrepreneurs (experimental) } \\
\hline Mean & 467.44 & 174.88 & 307.52 & 547.08 \\
\hline SD & 57.86 & 33.15 & 65.07 & 34.41 \\
\hline \multicolumn{5}{|c|}{ NFNE (control) } \\
\hline Mean & 499.80 & 199.00 & 323.72 & 474.52 \\
\hline SD & 54.47 & 39.62 & 57.88 & 75.82 \\
\hline$t$-statistic & 2.04 & 2.33 & 0.93 & 4.36 \\
\hline$P$-value & 0.04 & 0.02 & 0.35 & $<0.001$ \\
\hline Cohen's d & 0.58 & 0.66 & 0.26 & 1.23 \\
\hline
\end{tabular}

Note: Table includes results of $t$-tests, probabilities, and effect sizes.

Abbreviations: NFNE, nonfounders/nonentrepreneurs; RT, reaction time; $\mathrm{SD}$, standard deviation. 
reverse of the trend for N450 latency. Second, N450 latencies in the NFNE group were rather more dispersed than in the founder entrepreneur group, while the dispersions were comparable for N200 and P300 (see standard deviation values in Table 1).

No significant linear correlation was found between the N200 and N450 latencies, whether we considered the whole sample ( $r=-0.20, P=0.18$ for 50 individuals) and the two groups separately $(r=-0.22, P=0.30$ for 25 entrepreneurs, and $r=0.04, P=0.85$ for 25 controls).

No significant differences in ERP amplitudes were found between the groups (Table 2).

\section{Entrepreneurial nature of parents of participants in the study groups}

Regarding the entrepreneurial nature of parents, the groups were not homogeneous $\left(\chi_{1}^{2}=13.07, P<0.001\right) ; 68 \%$ $(\mathrm{n}=17)$ of founder entrepreneurs compared with $16 \%$ $(n=4)$ of NFNE had parents who were entrepreneurs. The possible confounding or modifying nature of this factor was considered when the selection of variables and factors associated with an entrepreneurial nature was carried out (logistic regression analyses).

\section{Effects of age}

In the case of age, the nature of the design, gender and agematched case-control study, avoids the potential confounder effect of age. Nevertheless, age may have a modifying effect (interaction) with other variables, including latencies and reaction times.

Ideally, the effect of aging should be assessed within a longitudinal study design but the retrospective nature of this study suggested that assessing this effect by means of linear regression analyses in the two groups, considering age as the independent variable and reaction times the N200 and

Table 2 Comparisons of ERP amplitudes (N200 uV, P300 uV, and $\mathrm{N} 450 \mathrm{uV}$ ) between founder entrepreneur and NFNE groups

\begin{tabular}{llll}
\hline & N200 uV & P300 uV & N450 uV \\
\hline $\begin{array}{llll}\text { Founder entrepreneurs } \\
\quad \text { Mean }\end{array}$ & 2.96 & -1.972 & -3.28 \\
SD & 1.398 & 1.106 & 1.429 \\
NFNE & & & \\
$\quad$ Mean & 2.92 & -1.836 & -2.68 \\
SD & 1.288 & 1.697 & 1.886 \\
z (Mann-Whitney) & -0.150 & -1.216 & -1.632 \\
$P$-value & 0.881 & 0.224 & 0.103 \\
\hline
\end{tabular}

Note: Table includes results of standardized Mann-Whitney statistics and probabilities. Abbreviations: NFNE, nonfounders/nonentrepreneurs; SD, standard deviation; ERP, event-related potentials.
N450 latencies as dependent variables. In these analyses, a positive or negative slope coefficient close to zero indicates the stability of reaction times and latencies across age in the control group (all $P$-values $>0.78$, according to the $t$-test of the slope of the regression line). Different results were found in the founder entrepreneur group, ie, reaction times increased with age, but not in a statistically significant manner $(P=0.1)$, while the N200 latency increased significantly with age $(P=0.04)$, with a close to significant decrease in N450 latency being observed $(P=0.08)$. The final decision about the modifying effect of age was carried out by adding the term "interaction" to the logistic model and evaluating both its biological meaning and its statistical significance.

\section{Gender effects}

As with age, it was necessary to analyze the possible interaction effect between gender and other covariates, ie, to examine whether the association between gender and latencies and reaction times change (or not) within the groups. The gender*group interaction term was not significant in the ANOVA tests relating to the three variables, ie, reaction times, and N200 and N450 latencies $\left(\mathrm{F}_{1,46}=0.03, P=0.865\right.$ for reaction time, $\mathrm{F}_{1,46}=1.25, P=0.27$ for $\mathrm{N} 200$, and $\mathrm{F}_{1,46}=3.08$, $P=0.09$ for N450). On the basis of these results, gender should not be considered as a candidate for the multivariate model in logistic regression analyses.

\section{Logistic regression analysis of personality, ERP latency, and reaction time}

We fitted a series of logistic regression equations to determine predictors of the nature of founder entrepreneurs. The dependent variable was "group" (founder entrepreneur or control). The independent (predictor) variables initially considered were the five temperament and character scores that showed statistical significance, reaction times, and N200 and N450 latencies. A specific analysis for age and the entrepreneurial nature of the parents was conducted. The logistic regression models were developed to predict the probability to belong to the founder entrepreneur group.

The variable selection process began with a careful univariate analysis of each variable using likelihood ratio tests with a $P$-value of 0.25 as the screening criterion to select candidate variables for the multivariate model. Due to the different nature of the predictors, we started the multivariate analysis with two separate blocks: the first for the temperament and character variables and the second for latencies and reaction times. Due to the different nature of the predictors, we started the multivariate analysis with two separate blocks: 
the first for the temperament and character variables and the second for latencies and reaction times. Logically, the five variables in the first block showed statistical significance.

Subsequently, a multivariate logistic model including the five selected variables was fitted. The relevance of each variable was verified by examination of its Wald test statistic; only two variables, ie, impulsivity $(P=0.005)$ and eagerness $(P=0.05)$, demonstrated a predictive power in the multivariate model. This suggested a new representative model that contained only the impulsivity and eagerness variables, and the $P$-values for this new model were 0.002 and 0.032 , respectively. The models containing five and two variables were compared via the likelihood ratio test $\left(\chi_{3}^{2}=0.65, P=0.88\right)$, showing that the three variables discarded (exploratory excitability, optimism, responsibility) added nonrelevant information to the model. At this point, it should be noted that the single model containing the impulsivity and eagerness variables provided a good fit in terms of the Nagelkerke $R^{2}$ statistic, 0.483 , and the classification table, ie, the sensitivity and specificity of model was $76 \%$ and $80 \%$, respectively, when a cutoff point of 0.50 was adopted. Univariate analysis corresponding to reaction times showed a significant association between these times with the group membership $(P=0.042)$.

The two latencies considered, ie, the N200 and N450, show a significant association with the group $(P=0.021$ and $P<0.001$, respectively). Subsequently, a multivariate logistic model including reaction times, and the N200 and N450 variables was fitted. Only the N450 latency was statistically significant ( $P=0.003$, Wald test). Reaction time and N200 latency did not add relevant information to the model containing only the N450 latency $\left(\chi_{2}^{2}=4.82, P=0.09\right)$. Again, it is important to emphasize that the model containing only the N450 latency provided a good fit (a Nagelkerke $R^{2}$ statistic of 0.390 , with a sensitivity of $80 \%$ and specificity of $64 \%$ ).

The next step in development of the model was to fit a new model containing all of the selected variables, ie, impulsivity, eagerness, and N450 latency. Multivariate analysis selected only impulsivity $(P=0.008)$ and N450 latency $(P=0.015)$. Taking into account the results concerning the "entrepreneurial nature of parents", an additional model was fitted to assess the confounder status of this covariate. Comparing the estimated coefficients for impulsivity and N450 latency from the models containing and not containing "entrepreneurial nature of parents", we concluded that this covariate is not a confounder.

The model-building process was continued by ascertaining the correct scale in the logit for impulsivity and the N450. This analysis showed evidence of linearity in both cases.
The next step in model development was assessment for the possibility of interaction between the variables. In addition, in view of our results for age, we sought to determine whether age interacts with any of the variables. Three interactions were significant or close to statistical significance, ie, impulsiveness*N450 $(P=0.012)$, impulsiveness*age $(P=0.059)$, and N450*age $(P=0.061)$. An additional model containing these interactions selected only the impulsivity*N450 interaction. Therefore, the model including impulsivity, N450 latency, and the impulsivity*N450 interaction was selected as the best model for discrimination between entrepreneurs and controls. The coefficients (and their $P$-values $)$ in the final model were: $-3.342(P=0.030)$ for impulsivity; $-0.136(P=0.039)$ for N450 latency; 0.007 $(P=0.021)$ for the impulsivity*N450 interaction; and 62.69 $(P=0.051)$ for the constant. The Hosmer-Lemeshow statistic was $7.21(P=0.514)$ and the Nagelkerke $R^{2}$ goodness of fit statistic was 0.647 , indicating that $64.7 \%$ of "variation" in the discrimination (founding entrepreneur versus NFNE) was explained by the logistic model.

A receiver-operating characteristic curve was used to evaluate the precision of the final model. The area under the receiver-operating characteristic curve was 0.898 with a $95 \%$ confidence interval of $0.808-0.987$. At the 0.5 cutoff point, sensitivity was 0.80 , specificity was 0.92 , and total classification accuracy was 0.81 . Figure 3 shows this curve.

In this approach, estimated probabilities are used to predict group membership. From the final fitted model, the estimated probability of belonging to the entrepreneur group increased when impulsivity increased and when N450 latency

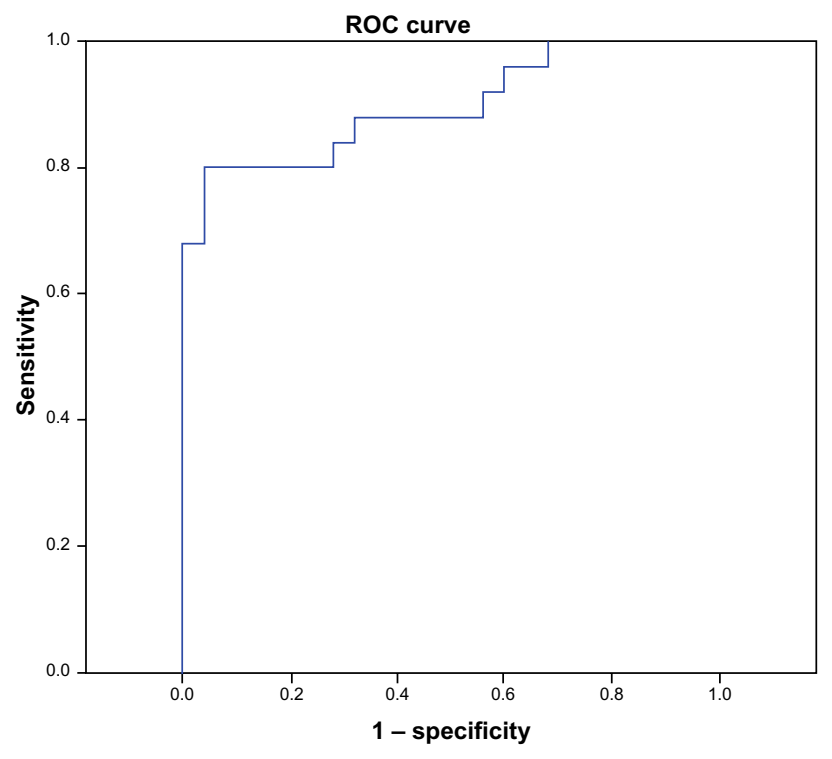

Figure 3 ROC curve for the results of the logistic regression model. Abbreviation: ROC, receiver-operating characteristic. 
increased, this probability being highest when both covariates were large. As an example, the estimated probability of belonging to the entrepreneur group for an individual with values of 27.16 for impulsivity and 547.08 for N450 latency (average values of the entrepreneur group) was 0.921 . The probability for an individual with values of 22.12 for impulsivity and 474.52 for N450 latency (average values of the control group) was 0.191 .

\section{Source localization}

During the Stroop task color response, maximal activation in N200 was seen in the right temporal area in both groups and in the occipital and frontal areas in founder entrepreneurs. Both groups showed activation of multimodal temporoparieto-occipital areas in P300, yet they differed slightly, with higher activation seen in the right frontal lobe in the founder entrepreneur group. Finally, the N450 showed maximal activation in right temporofrontal lobes in founder entrepreneurs, while in the NFNE group, the activation was in the left frontal, right temporal, and bilateral parietal areas (Figure 4 and Table 3).

\section{Differences in source localization between groups}

Using statistical mapping, significant differences in the N200 were found between the groups during the Stroop reaction time task, with higher activation in supplementary areas bilaterally in the founder entrepreneur group and higher activation in the left occipital area in the NFNE group. In contrast, differences in the N450 were found in the left inferior frontal areas in favor of the founder entrepreneur group (Figure 5 and Table 4). No significant differences were found in the $\mathrm{P} 300$.

\section{Discussion}

Identifying "entrepreneurial thinking" has been the aim of many studies, ${ }^{4}$ but this is far from being fully elucidated. Our study focused on what we considered to be the first step of this phenomenon, ie, how decision-making regarding an ambiguous and unfamiliar task differs between founder entrepreneurs and NFNE and what are the parameters that differentiate these two groups. In the following sections, we review the decisionmaking process during a Stroop task in founder entrepreneurs and NFNE. The following discussion explains the differences between these groups in relation to personality, behavioral responses, ERPs, and their respective brain areas.

\section{Differences in temperament and character}

Our results show that, in relation to personality, the noveltyseeking parameter is the only one that yields significant differences. Its subscales "exploratory excitability" and "impulsiveness" are prominent in founder entrepreneurs. With regard to the other personality dimensions, some

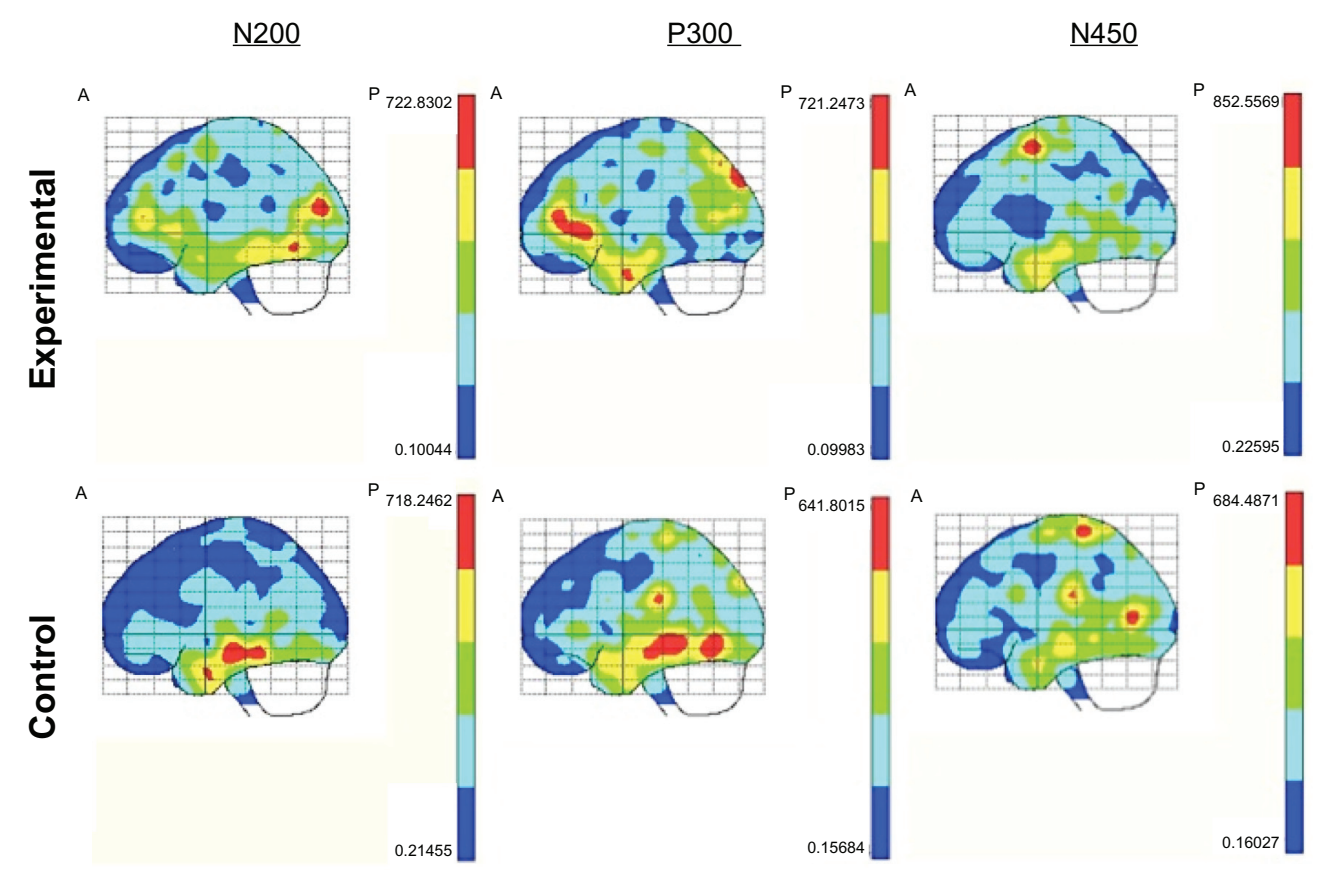

Figure 4 Mean maps source analysis (LORETA) obtained in N200, P300, and N450 in both groups during the Stroop task. Maximal intensity projection areas are displayed in red.

Abbreviations: A, anterior; P, posterior; LORETA, low-resolution electromagnetic tomography. 
Table 3 Summary of mean maximal intensity projection areas indicating specific localization in both groups during the Stroop task in $\mathrm{N} 200, \mathrm{P} 300$, and N450

\begin{tabular}{|c|c|c|c|c|c|c|c|}
\hline & \multirow[t]{2}{*}{ Wave } & \multirow[t]{2}{*}{ AAL } & \multirow[t]{2}{*}{ BA } & \multicolumn{3}{|c|}{ MNI coordinates } & \multirow{2}{*}{$\begin{array}{l}\text { Tomography } \\
\text { value }\end{array}$} \\
\hline & & & & $x$ & $\mathbf{Y}$ & $\mathbf{Z}$ & \\
\hline \multirow[t]{25}{*}{ Experimental } & N200 & Occipital Mid R & 19 & 42 & -82 & 16 & 710.7058 \\
\hline & & Temporal Inf R & 37 & 54 & -62 & -8 & 605.9977 \\
\hline & & Frontal Mid R & 45 & 46 & 46 & 12 & 581.7214 \\
\hline & & Frontal Inf Tri R & 45 & 50 & 22 & 0 & 476.2250 \\
\hline & & Temporal Mid R & 20 & 62 & -26 & -16 & 473.4678 \\
\hline & P300 & Cuneus R & 19 & 14 & -86 & 36 & 668.1757 \\
\hline & & Occipital Sup R & 19 & 18 & -82 & 36 & 667.5593 \\
\hline & & Frontal Mid R & 45 & 46 & 46 & 8 & 635.7744 \\
\hline & & Frontal Inf Tri R & 45 & 50 & 30 & 3 & 604.5015 \\
\hline & & Frontal Inf Orb R & 47 & 50 & 26 & -4 & 594.8906 \\
\hline & & Temporal Inf R & 20 & 54 & -6 & -32 & 593.3781 \\
\hline & & Precuneus L & 7 & -2 & -70 & 48 & 580.7664 \\
\hline & & Parietal Sup R & 7 & 18 & -82 & 48 & 513.3035 \\
\hline & & Temporal Mid R & 20 & 50 & 2 & -2 & $513.137 \mid$ \\
\hline & & Frontal Inf Oper R & 47 & 46 & 18 & 0 & 503.6279 \\
\hline & & Temporal Pole Mid R & 21 & 50 & 6 & -24 & 494.2846 \\
\hline & & Occipital Mid R & 39 & 46 & -78 & 16 & 471.9835 \\
\hline & & Parietal Sup L & 7 & -14 & -74 & 44 & 448.2806 \\
\hline & & Precuneus R & 7 & 6 & -70 & 44 & 439.2010 \\
\hline & N450 & Frontal Mid R & 6 & 34 & 2 & 60 & 852.5569 \\
\hline & & Frontal Sup R & 6 & 30 & 2 & 64 & 750.3677 \\
\hline & & Temporal Mid R & 21 & 54 & -2 & -28 & 667.9053 \\
\hline & & Temporal Inf R & 20 & 50 & -2 & -36 & 585.6037 \\
\hline & & Temporal Pole Mid R & 21 & 50 & 6 & -24 & 570.5635 \\
\hline & & Supp Motor Area R & 6 & 10 & 2 & 68 & 545.4234 \\
\hline \multirow[t]{27}{*}{ Control } & N200 & Temporal Mid R & 21 & 62 & -18 & -16 & 672.3378 \\
\hline & & Temporal Inf R & 20 & 62 & -38 & -16 & 605.5762 \\
\hline & & Temporal Sup R & 22 & 62 & -14 & -8 & 566.0411 \\
\hline & & Temporal Pole Mid R & 21 & 50 & 6 & -24 & 499.3273 \\
\hline & P300 & Temporal Inf L & 37 & -54 & -66 & -8 & 630.2206 \\
\hline & & Temporal Mid L & 21 & -66 & -34 & -8 & 622.9046 \\
\hline & & Temporal Mid R & 21 & 66 & -18 & -16 & 556.1460 \\
\hline & & Supramarginal L & 2 & -66 & -26 & 24 & 544.6680 \\
\hline & & Postcentral L & 2 & -66 & -22 & 24 & 521.7436 \\
\hline & & Occipital Inf L & 37 & -54 & -66 & -16 & 492.2468 \\
\hline & & Paracentral Lobule R & 4 & 2 & -30 & 68 & 468.5005 \\
\hline & & Occipital Sup L & 19 & -18 & -86 & 36 & 466.9942 \\
\hline & & Paracentral Lobule L & 4 & -2 & -30 & 68 & 455.6725 \\
\hline & & Temporal Inf R & 20 & 50 & -2 & -36 & 421.7493 \\
\hline & & Temporal Sup R & 22 & 62 & -18 & -4 & 407.6608 \\
\hline & & Temporal Sup L & 22 & -54 & -6 & -12 & 398.5413 \\
\hline & N450 & Paracentral Lobule R & 4 & 2 & -34 & 68 & 624.3183 \\
\hline & & Temporal Mid R & 37 & 54 & -66 & 8 & 604.8766 \\
\hline & & Paracentral Lobule L & 4 & -6 & -34 & 68 & 580.1621 \\
\hline & & Supramarginal L & 2 & -66 & -26 & 24 & 563.2433 \\
\hline & & Parietal Sup R & 5 & 18 & -50 & 72 & 544.7388 \\
\hline & & Precuneus L & 5 & -14 & -50 & 72 & 483.5905 \\
\hline & & Postcentral R & 3 & 26 & -34 & 72 & 467.7926 \\
\hline & & Temporal Sup R & 22 & 62 & -18 & -4 & $45 I .4284$ \\
\hline & & Supp Motor Area L & 6 & -6 & -10 & 68 & 446.7787 \\
\hline & & Postcentral L & 48 & -66 & -18 & 20 & 426.8743 \\
\hline & & Temporal Mid L & 21 & -66 & -38 & -8 & 421.8962 \\
\hline
\end{tabular}

Abbreviations: AAL, anatomic label corresponding to Probabilistic Brain Atlas; BA, Brodmann areas; X, Y, Z = MNI, Montreal National Institute coordinates; R, right; L, left; Mid, middle; Inf, inferior; Orb, orbital; Tri, triangular; Sup, superior; Supp, supplementary; Oper, opercular. 
N200
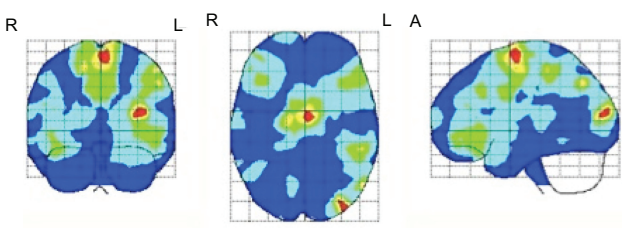

$\mathrm{R}$ N450
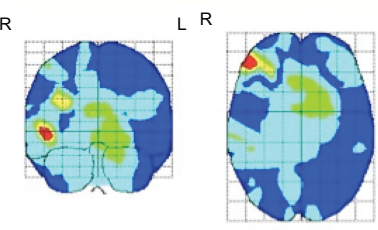

L A

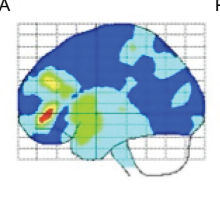

$P_{29.31662}$

29.31700

Figure 5 Statistical mapping using independent Hotelling's T-squared test showing significant differences in maps between founder entrepreneur and NFNE groups during different tasks in the N200-N450 waves.

Abbreviations: R, right; L, left; A, anterior; P, posterior; NFNE, nonfounder/ nonentrepreneur.

specific subscales were found to be significant as well, ie, responsibility (belongs to self-directness), optimism (belongs to harm avoidance), and eagerness of effort (belongs to persistence).

Exploratory excitability and impulsiveness could be associated with riskier behavior, interest in new ideas and activities, but also intolerance of monotony and boredom. These dimensions are more prominent in founder entrepreneurs and match with the overall personality one might anticipate in this group. Lawrence et $\mathrm{al}^{62}$ labeled this entrepreneur impulsivity trait "functional impulsivity", ie, something more related to activity, enthusiasm, and adventurousness. ${ }^{63}$ High scores on eagerness of effort may be related to pursuit of achievement by entrepreneurs. ${ }^{64-67}$ Again, this group is behaviorally characterized by achievement and persistence. Other researchers have reported similar results and consider motivation and optimism to be traits characteristic of personality in entrepreneurs. ${ }^{68}$

\section{Differences in reaction times and ERP latencies}

Reaction times indicated that founder entrepreneurs made faster decisions than did NFNE, both behaviorally (shorter reaction times), and neurophysiologically (N200). The faster reaction times and shorter N200 latency seen in founder entrepreneurs could be related to their better capacity for selective visual attention, ${ }^{69}$ response selection, and executive control. The latter two cognitive processes are associated with response inhibition..$^{16,17}$

Selective visual attention facilitates analysis of relevant information by omitting distracting information. This is a process aided by previous learning. ${ }^{69-73}$ One might speculate that entrepreneurs are more accustomed to monitoring their environment in a persistent fashion in order to extract relevant information for a better response. Indeed, Gaglio and $\mathrm{Katz}^{74}$ suggested that entrepreneurs may have "entrepreneurial alertness", which they defined as a cognitive framework that assists such persons in being alert to opportunities. The N200 and reaction time may also be explained by faster decision-making by entrepreneurs in a scenario of only partial and variable information. ${ }^{7,75-79}$ Entrepreneurs may be able to make faster decisions based on partial information due to cognitive mechanisms ${ }^{80}$ and pattern recognition, even if it is a complex one against a noisy background ${ }^{81}$ The earlier N200 latency seen in founder entrepreneurs may be influenced by their functional impulsivity, ie, a tendency to act with relatively little forethought. ${ }^{62,63}$ On the other hand, impulsivity has been reported as a key factor influencing very basic perceptual and memory processes..$^{82-88}$

It would seem that founder entrepreneurs may have better skills for adaptation and modulation of their behavior according to the goal they are pursuing, ie, their attention is focused on goal-relevant information that will enhance selection of a response. ${ }^{89,90}$ Founder entrepreneurs also employ fast and simple rules to adapt their representative

Table 4 Summary of statistically significant differences in maximal intensity projection areas, indicating specific localization for each group (independent Hotelling's T-squared test)

\begin{tabular}{llllllll}
\hline AAL & BA & $\mathbf{X}$ & $\mathbf{Y}$ & $\mathbf{Z}$ & $\begin{array}{l}\mathbf{T}^{2} \text { Hotelling } \\
\text { test }\end{array}$ & Experimental & Control \\
\hline N200 & & & & & & & \\
$\quad$ Occipital Mid L & 19 & -38 & -90 & 16 & 29.3166 & 75.8676 & 131.1018 \\
$\quad$ Supp Motor Area L & 6 & -2 & -6 & 72 & 28.6554 & 38.7641 \\
$\quad$ Supp Motor Area R & 6 & 14 & -10 & 56 & 23.6681 & & 120.0736 \\
N450 & & & & & & 247.2091 & 10.2807 \\
$\quad$ Frontal Inf Orb R & 46 & 46 & 46 & -4 & 28.9879 & 259.2958 & 185.0241 \\
$\quad$ Frontal Inf Tri R & 45 & 46 & 42 & 0 & 28.0539 & 192.5863 \\
\hline
\end{tabular}

Note: $P<0.01$

Abbreviations: AAL, anatomic label corresponding to Probabilistic Brain Atlas; BA, Brodmann areas; X, Y, Z, Montreal National Institute coordinates from the Probabilistic Brain Atlas in three spatial axes; L, left; R, right; Mid, middle; Inf, inferior; Orb, orbital; Tri, triangular. 
heuristic decision responses in response to changes in the informational context. ${ }^{91}$ On the other hand, attention directed towards a given stimulus precludes other cognitive processes which could delay decision-making. ${ }^{92-96}$

The N200 during a Stroop paradigm reflects detection of conflict and its resolution. It indicates the amount of resources recruited for monitoring of conflict, novelty detection, and sequential mapping processes. ${ }^{97}$ Some authors have stated that this reflects pre-response conflict during correct trials. ${ }^{98}$ Based on this literature, founder entrepreneurs may be better at detecting conflict and resolving it rapidly.

However, an alternative explanation cannot be overlooked. Some authors state that the N200 maximal amplitude, and conflict, depends upon the individual's ability to consider an alternative response. ${ }^{98}$ Furthermore, N200 latency was found in several studies to be correlated with reaction time. ${ }^{98}$ However, reaction time in the Stroop task depends on the individual's internal criterion with regard to whether or not they prefer swiftness of response over accuracy, ie, the response-accuracy tradeoff. Entrepreneurs might have been inclined to react faster, risking more false responses as a tradeoff, yet we found no behavioral differences in error rates or correct answers between our two groups. Correlates of this different criterion (compared with the control group) are the faster reaction time and N200. Obviously, this would also fit with the greater impulsivity reported for entrepreneurs, because an impulsive person would tend to trade speed for accuracy. This alternative explanation would indicate that N200 is not related to the quality of conflict detection, but is more difficult to prove given the lack of difference in errors and correct answers between the two groups.

The more prolonged N450 latency in the experimental group suggests that founder entrepreneurs need more time to complete all cognitive processes linked to decisionmaking. The N450 has been replicated several times in Stroop paradigms and can be considered a robust marker of conflict processing in ERP studies. However, this delay is not related to either detection or resolution of conflict in the Stroop paradigm. ${ }^{99-102}$ The N450 is a more general marker of an abstract level of conflict ${ }^{101,102}$ and is linked to cognitive monitoring of a decision that has already been taken, although stimulus conflict could also influence the N450 (latency). This suggests that founder entrepreneurs are slower and more cautious than the controls in evaluating their decisions. Sarasvathy ${ }^{103}$ contends that entrepreneurial decision-making is often far from linear.

On the other hand, the N450 has been found to be associated with access to memory during generation and maintenance of visual images. ${ }^{30,104-107}$ Working memory has been invoked as a key factor that may explain differences between individuals when dealing with highly complex cognitive tasks. ${ }^{1}$ We did not address this issue specifically, but future research will need to take into account the N450 and working memory when differentiating between founder entrepreneurs and NFNE.

\section{Differences in ERP (N200/N450) source localization}

Founder entrepreneurs can also be differentiated by the brain location with regard to two cognitive process, ie, an early one associated with motor response initiation (N200), mostly localized around supplementary motor areas, and a late one (N450) linked to integrative cognitive processes, which serve to analyze and evaluate a given response, mainly in the anterior frontal regions.

The N200 reflects pre-response processing during decision-making tasks. Differences in maximal brain activity at this stage were found bilaterally in supplementary motor areas. These areas have already been described as part of a network, which includes the inferior parietal sulcus, for the "how" of achieving goals and enables the subject to make subsequent choices. ${ }^{108,109}$

The N450 is associated with completion of cognitive processes linked to decision-making. Differences were found between founder entrepreneurs and NFNE in the prefrontal areas. Within the prefrontal area, the orbitofrontal cortex represents a region of abstract value information that codes for differences between the perceived value of goods. ${ }^{109,110}$

\section{Neurocognitive differences}

The prefrontal area is responsible for top-down control and adjustment of performance. ${ }^{42}$ Some authors have formulated the hypothesis of a frontal cognitive unitary process for the attentional and control demands of decision-making. ${ }^{90}$ From this point of view, the N450 can be seen as an extension of the N200. ${ }^{34,39,42}$ However, other researchers have suggested that the N450 is a peak that is clearly distinct from that of the N200. ${ }^{31}$ Thus, the delay in N450 latency and its greater predominance in the frontal areas suggest that founder entrepreneurs need greater brain resources for decision-making. These brain resources refer to processing of the decision outcome, which requires more time and higher activation in the frontal areas. In any case, the relationship between the N200 and N450 may be a complex one, and a possible alternative explanation has to be taken into account. The safest result arises from longer processing of the decision 
outcome in founder entrepreneurs, and points towards more thorough processing of such outcomes in the founder entrepreneur group. The greater need for attentional resources would have had an impact on P300 or N450 amplitudes, but this was not the case.

The greater N450 activity seen in the prefrontal area could be associated with increased cortical resources during final decision analysis. N450 negativity is more marked in the frontal anterior areas of founder entrepreneurs. This may be linked to integration of knowledge concerning cognitive processing. ${ }^{106,107}$ The last stage of cognitive processing related to decision-making may be associated with several kinds of higher level functions ${ }^{105}$ during which founder entrepreneurs consume more energy and need more time than NFNE to finish their cognitive processing. In this time frame, the response tends to become more negative as missing information is added to an incomplete or ambiguous object, rendering it more clearly associated with closure. Several studies have demonstrated prefrontal activity during this later time frame and have provided evidence for a functional network between the visual and frontal cortices, with the prefrontal area hypothesized to mediate matching between degraded sensory information and stored representations. ${ }^{111,112}$

Emotionally neutral decisions unaffected by reward and/or punishment are sometimes referred to as cold processes. They are considered to depend upon the dorsolateral prefrontal area. ${ }^{113}$ The Stroop task belongs to the category of cold processes. Although it is arguable that decisions related to a company made by entrepreneurs are not devoid of reward or punishment, some authors have stated that cold processes govern real-life decisions, such as planning the details related to opening a new company branch. ${ }^{62}$

\section{Final considerations}

Some authors have contended that entrepreneurs do have a unique mindset and orientation. ${ }^{114,115}$ They differ cognitively from many in the general population and may be more competitively advantaged for dynamic business environments. ${ }^{49}$

Hisrich et $\mathrm{a}^{116}$ have suggested that cognitive shortcuts (eg, heuristics, more specifically representativeness heuristics) for decision-making could distinguish entrepreneurs from nonentrepreneurs and help to account for their different patterns of risk perception. ${ }^{51,117,118}$ Cognitive shortcuts may be the only way forward for entrepreneurs, given the emotional constraints, fatigue, information overload, novelty, uncertainty, and time pressures normally associated with their work. ${ }^{51,91,119}$
Entrepreneurs make sense of ambiguous, uncertain, and complex situations more readily than many in the general population, and may even learn faster as a result of this skill. ${ }^{49}$ Our supplementary motor area and reaction time findings support this contention. Founder entrepreneurs need less time to visualize stimuli before making a decision, a task carried out mainly in the occipital area. Greater attention to relevant stimuli has been postulated to explain this phenomenon. ${ }^{120}$ Founder entrepreneurs show a longer time for post-evaluation (N450). Some authors have postulated a complex interaction between systems affecting memory, active searching, attention, complex computations, establishing comparisons, decision-making, and checking of answers. $^{120}$

Based on the above discussion and taking our results into account, we conclude that founder entrepreneurs make decisions based on blurred and conflicting information differently from NFNE. ${ }^{51}$ Entrepreneurs seem to have a faster decision-making process because closure of their decision happens earlier, but they are more alert to opportunities. ${ }^{1}$ In this respect, entrepreneurs might be more oriented towards opportunity recognition and capture, and eager to make more rapid decisions about which opportunities to pursue. Subsequently, however, they dedicate significant cognitive resources to decision closure and resolution of residual conflicts. Entrepreneurs have to invest more mental effort in this process, partly because they need to check the decisions they have just made. ${ }^{1}$ They assemble information and resources differently, in a nontraditional and nonlinear manner. ${ }^{103}$

Amongst the most important limitations of our study are its relatively small study population and the aspects inherent in the choice to use a Stroop task. Ideally, a more businessorientated test could have yielded more specific information about decision-making in founder entrepreneurs; however, the Stroop task remains a widely used tool, is very well validated, and is a gold standard for the study of rapid decisions based on conflicting information. Our study has did not address differences within the founder entrepreneur group, ie, our experimental group, and more refined selection may have been more precise, although it could have rendered obtaining a sample simply nonviable. This experiment would also have benefited from another control group comprising managers with characteristics and experience similar to that of the founder entrepreneur group.

There are still huge gaps in research differentiating entrepreneurs from nonentrepreneurs in terms of neurobiology. A search using the National Institutes of Health engine 
yielded not one result for $<$ entrepreneur $>$ and $(<$ EEG $>$ or $<$ ERP $>$ ). Our research is a first step towards exploration of this field and we have accomplished it using a high-density (128-channel) EEG device. On the other hand, personality is an issue seldom taken into account in neurobiological studies of this kind, but is likely to be very influential. We addressed this problem by using the most neurobiologic personality instrument available. Finally, we dealt adequately with the potential confounding factor of being a descendant of entrepreneurs.

Establishing the brain networks for decision-making is far from being fully elucidated. ${ }^{109}$ There is a substantial body of research using functional magnetic resonance imaging for this purpose, yet the temporal resolution of this neuroimaging technique is about 4 seconds. Therefore, it is imperative to clarify what happens in the brain during the first moments when a decision is being made. EEG offers a unique window in this regard because its temporal resolution is in the range of milliseconds and it provides an opportunity to perform electrical source localization at low cost.

Entrepreneurs are able to identify a need and do something about it, but it remains unclear why other people do not follow a similar path to that of entrepreneurs. An important issue is the decision-making challenges entrepreneurs face in real life, and their response to these issues. Based on the results of our experiment, impulsivity and N450 latency, as well as their interaction, are the covariates that differentiate most between entrepreneurs and NFNE. These covariates are related to other covariates, such as reaction time and N200 latency, which help to distinguish between these two groups.

\section{Acknowledgments}

The authors would like to thank the IE Business School, Madrid, Spain, for supporting this research. They are also grateful to Professor Robert Cloninger (Washington University, St Louis, MO, USA) and Gabriel A de Erausquin (University of South Florida, Tampa, FL, USA) for their help and assistance with the TCI-R.

\section{Disclosure}

The funding body of this research (IE) had no part in the design of this experiment, data acquisition, analyses, and/or writing of the manuscript. The authors declare no individual or collective conflict of interest of any kind in relation to this work.

\section{References}

1. Baron R, Ward T. Expanding entrepreneurial cognition's toolbox: potential contributions from the field of cognitive science. Entrepreneurship Theory and Practice Journal. 2004;28:553-573.
2. Martin LE, Potts GF. Impulsivity in decision-making: an event-related potential investigation. Pers Individ Dif. 2009;46:303-308.

3. Smith PL, Ratcliff R. Psychology and neurobiology of simple decisions. Trends Neurosci. 2004;27:161-168.

4. Grégoire D, Corbett A, McMullen J. The cognitive perspective in entrepreneurship: an agenda for future research. J Manage Stud. 2011;48:6.

5. Zhao H, Seibert SE. The big five personality dimensions and entrepreneurial status: a meta-analytical review. J Appl Psychol. 2006;91: 259-271.

6. Gómez CM, Flores A. A neurophysiological evaluation of a cognitive cycle in humans. Neurosci Biobehav Rev. 2011;35:452-461.

7. Töllner T, Rangelova D, Müllera H. How the speed of motor-response decisions, but not focal-attentional selection, differs as a function of task set and target prevalence. Proc Natl Acad Sci U S A. 2012;109: E1990-E1999.

8. McCallum WC, Curry SH, Cooper R, Pocock PV, Papakostopoulos D. Brain event-related potentials as indicators of early selective processes in auditory target localization. Psychophysiology. 1983;20: $1-17$.

9. Rösler F, Heil M, Röder B. Slow negative brain potentials as reflections of specific modular resources of cognition. Biol Psychol. 1997;45: 109-141.

10. Birbaumer N, Elbert T, Canavan AG, Rockstroh B. Slow potentials of the cerebral cortex and behavior. Physiol Rev. 1990;70:1-41.

11. Khader P, Heil M, Rösler F. Material-specific long-term memory representations of faces and spatial positions: evidence from slow event-related brain potentials. Neuropsychologia. 2005;43: 2109-2124.

12. Khader P, Ranganath C, Seemüller A, Rösler F. Working memory maintenance contributes to long-term memory formation: evidence from slow event-related brain potentials. Cogn Affect Behav Neurosci. 2007;7:212-224.

13. Jost K, Beinhoff U, Hennighausen E, Rösler F. Facts, rules, and strategies in single-digit multiplication: evidence from event-related brain potentials. Brain Res Cogn Brain Res. 2004;20:183-193.

14. Khader P, Schicke T, Röder B, Rösler F. On the relationship between slow cortical potentials and BOLD signal changes in humans. Int $J$ Psychophysiol. 2008;67:252-261.

15. Luck SJ, Hillyard SA. Spatial filtering during visual search: evidence from human electrophysiology. J Exp Psychol Hum Percept Perform. 1994;20:1000-1014.

16. Pfefferbaum A, Ford JM, Weller BJ, Kopell BS. ERPs to response production and inhibition. Electroencephalogr Clin Neurophysiol. 1985;60:423-434

17. Falkenstein M, Hoormann J, Hohnsbein J. ERP components in Go/Nogo tasks and their relation to inhibition. Acta Psychol (Amst). 1999;101: 267-291.

18. Nieuwenhuis S, Holroyd CB, Mol N, Coles MG. Reinforcement-related brain potentials from medial frontal cortex: origins and functional significance. Neurosci Biobehav Rev. 2004;28:441-448.

19. Squire LR, Slater PC, Chace PM. Retrograde amnesia: temporal gradient in very long-term memory following electroconvulsive therapy. Science. 1975; 187:77-79.

20. Donchin E, Coles MGH. Is the P300 component a manifestation of cognitive updating? Behav Brain Sci. 1988;1:357-427.

21. Ruchkin DS, Johnson R Jr, Canoune HL, Ritter W, Hammer M. Multiple sources of $\mathrm{P} 3 \mathrm{~b}$ associated with different types of information. Psychophysiology. 1990;27:157-176.

22. Dowman R. Neural mechanisms of detecting and orienting attention toward unattended threatening somatosensory targets. I. Intermodal effects. Psychophysiology. 2007;44:407-419.

23. Friedman D, Cycowicz YM, Gaeta H. The novelty P3: an event-related brain potential (ERP) sign of the brain's evaluation of novelty. Neurosci Biobehav Rev. 2001;25:355-373.

24. Sutton S, Baren M, Zubin J, John ER. Evoked potentials correlates of stimulus uncertainty. Science. 1965;150:1187-1188. 
25. McCarthy G, Wood CC. Intracranial recordings of endogenous ERPs in humans. Electroencephalogr Clin Neurophysiol Suppl. 1987;39: 331-337.

26. Lockwood AH, Wack DS, Benedict RH, Coad ML, Sussman JE, Burkard RF. Multi-site phasic neural activity mediates the execution of an auditory continuous performance task: a PET and electrophysiological study. J Neuroimaging. 2008;18:364-374.

27. Railo H, Koivisto M, Revonsuo A. Tracking the processes behind conscious perception: a review of event-related potential correlates of visual consciousness. Conscious Cogn. 2011;20:972-983.

28. Legrain V, Guérit JM, Bruyer R, Plaghki L. Attentional modulation of the nociceptive processing into the human brain: selective spatial attention, probability of stimulus occurrence, and target detection effects on laser evoked potentials. Pain. 2002;99:21-39.

29. Van Petten C, Luka BJ. Neural localization of semantic context effects in electromagnetic and hemodynamic studies. Brain Lang. 2006;97: 279-293.

30. Kutas M, Federmeier KD. Thirty years and counting: finding meaning in the N450 component of the event related brain potential (ERP). Annu Rev Psychol. 2011;62:621-647.

31. Liotti M, Woldorff MG, Perez R, Mayberg HS. An ERP study of the temporal course of the Stroop color-word interference effect. Neuropsychologia. 2000;38:701-711.

32. Perlstein WM, Larson MJ, Dotson VM, Kelly KG. Temporal dissociation of components of cognitive control dysfunction in severe TBI: ERPs and the cued-Stroop task. Neuropsychologia. 2006;44:260-274.

33. West R. Neural correlates of cognitive control and conflict detection in the Stroop and digit location tasks. Neuropsychologia. 2003;41: 1122-1135.

34. West R, Alain C. Event-related neural activity associated with the Stroop task. Brain Res Cogn Brain Res. 1999;8:157-164.

35. West R, Alain C. Effects of task context and fluctuations of attention on neural activity supporting performance of the Stroop task. Brain Res. 2000;873:102-111.

36. West R, Jakubek K, Wymbs N, Perry M, Moore K. Neural correlates of conflict processing. Exp Brain Res. 2005;167:38-48.

37. Szucs D, Soltesz F, White S. Motor conflict in Stroop tasks: direct evidence from single-trial electro-myography and electroencephalography. Neuroimage. 2009;47:1960-1973.

38. Appelbaum LG, Meyerhoff KL, Woldorff MG. Priming and backward influences in the human brain: processing interactions during the Stroop interference effect. Cereb Cortex. 2009;19:25008-25021.

39. Van Veen V, Carter CS. The anterior cingulate as a conflict monitor: fMRI and ERP studies. Physiol Behav. 2002;77:477-482.

40. West R, Bowry R, McConville C. Sensitivity of medial frontal cortex to response and nonresponse conflict. Psychophysiology. 2004;41: 739-748.

41. Botvinick M, Nystrom LE, Fissel K, Carter SC, Cohen JD. Conflict monitoring versus selection for action in anterior cingulate cortex. Nature. 1999;402:179-181.

42. Botvinick M, Cohen JD, Carter CS, Braver TS, Barch DM. Conflict monitoring and cognitive control. Psychol Rev. 2001;108:624-652.

43. Botvinick M, Cohen JD, Carter CS. Conflict monitoring and anterior cingulate cortex: an update. Trends Cogn Sci. 2004;8:539-546.

44. Liston C, Matalon S, Hare TA, Davidson MC, Casey BJ. Anterior cingulate and posterior parietal cortices are sensitive to dissociable forms of conflict in a task-switching paradigm. Neuron. 2006;50: 643-653.

45. Egner T, Delano M, Hirsch J. Separate conflict-specific cognitive control mechanisms in the human brain. Neuroimage. 2007;35:940-948.

46. Van Veen V, Carter SC. Separating semantic conflict and response conflict in the Stroop task: a functional fMRI study. Neuroimage. 2005;27:497-504.

47. Kerns JG. Anterior cingulate and prefrontal cortex activity in an fMRI study of trial-to-trial adjustments on the Simon task. Neuroimage. 2006;33:399-405.

48. Lansbergen MM, van Hell E, Kenemans JL. Impulsivity and conflict in the Stroop task: an ERP study. J Psychophysiol. 2007;21:33-50.

49. Alvarez SA, Busenitz LW. The entrepreneurship of resource-based theory. J Manage. 2001;27:755-775.
50. Mitchell RK, Busenitz LW, Lant T, McDougall PP, Morse EA, Smith JB. Toward a theory of entrepreneurial cognition: rethinking the people side of entrepreneurship research. Entrepreneurship Theory and Practice Journal. 2002;27:93-104.

51. Busenitz LW, Barney JB. Differences between entrepreneurs and managers in large organizations: biases and heuristics in strategic decision-making. Journal of Business Venturing. 1997;12:9-30.

52. Sarasvathy SD. The questions we ask and the questions we care about: reformulating some problems in entrepreneurship research. Journal of Business Venturing. 2004;19:707-717.

53. Gutiérrez-Zotes JA, Bayón C, Montserrat C, et al. Inventario del temperamento y el carácter-revisado (TCI-R). Baremación y datos normativos en una muestra de población general [Temperament and Character Inventory Revised (TCI-R). Standardization and normative data in a general population sample]. Actas Españolas de Psiquiatría. 2004;32:8-15. Spanish.

54. Pascual-Marqui RD, Michel CM, Lehmann D. Low resolution electromagnetic tomography: a new method for localizing electrical activity in the brain. Int J Psychophysiol. 1994;18:49-65.

55. Pascual-Marqui RD. Review of methods for solving the EEG inverse problem. Int J Bioelectromagn. 1999;1:75-86.

56. Ortiz T, Poch J, Santos JM, et al. Recruitment of occipital cortex during sensory substitution training linked to subjective experience of seeing in people with blindness. PLoS One. 2011;6:e23264.

57. Pascual-Marqui RD, Esslen M, Kochi K, Lehmann D. Functional imaging with low resolution brain electromagnetic tomography (LORETA): review, new comparisons, and new validation. Methods Find Exp Clin Pharmacol. 2002;24 Suppl C:91-95.

58. Collins DL, Neelin P, Peters TM, Evans AC. Automatic 3D intersubject registration of MR volumetric data in standardized Talairach space. J Comput Assist Tomogr. 1994;18:192-205.

59. Mazziotta JC, Toga AW, Evans A, Fox P, Lancaster J. A probabilistic atlas of the human brain: theory and rationale for its development. The International Consortium for Brain Mapping (ICBM). Neuroimage. 1995;2:89-101.

60. Hosmer DW, Lemeshow S. Applied Logistic Regression. New York, NY: John Wiley \& Sons Inc; 1989.

61. Cohen J. Statistical Power Analysis for the Behavioral Sciences. 2nd ed. Hillsdale, NJ: Lawrence Erlbaum; 1988

62. Lawrence A, Clark L, Labuzetta JN, Sahakian B. The innovative brain. Nature. 2008;456:168-169.

63. Dickman SJ. Functional and dysfunctional impulsivity: personality and cognitive correlates. J Pers Soc Psychol. 1990;58:95-102.

64. Boyatzis RE. Competence at work. In: Stewart AJ, editor. Motivation and Society. San Francisco, CA: Jossey-Bass; 1982.

65. Gartner WB. Who is an entrepreneur? Is the wrong question. American Journal of Small Business. 1988;12:11-32.

66. Genescá E, Capelleras JL. Un análisis comparativo de las características de las microempresas en España [A comparative analysis of the characteristics of micro-enterprises in Spain]. Univ Bus Rev. 2004;2:72-93. Spanish.

67. Veciana JM. Características del empresario en España [Characteristics of the Spanish entrepreneur]. Papeles de Economía Española. 1989;39:19-36. Spanish.

68. Puga J, García J. Optimismo, pesimismo y realismo disposicional en emprendedores potenciales de base tecnológica [Optimism, pessimism and dispositional realism in potential technology-based entrepreneurs]. Psicothema. 2011;23: 611-616. Spanish.

69. Della Libera C, Perlato A, Chelazzi L. Dissociable effects of reward on attentional learning: from passive associations to active monitoring. PLoS One. 2011;6:e19460.

70. Chun MM, Turk-Browne NB. Interactions between attention and memory. Curr Opin Neurobiol. 2007;17:177-184.

71. Chun MM, Golomb JD, Turk-Browne NB. A taxonomy of external and internal attention. Annu Rev Psychol. 2011;62:73-101.

72. Desimone R. Neural mechanisms for visual memory and their role in attention. Proc Natl Acad Sci US A. 1996;93:13494-13499. 
73. Kristjánsson Á, Campana G. Where perception meets memory: a review of priming in visual search. Atten Percept Psychophys. 2010;72: 5-18.

74. Gaglio CM, Katz J. The psychological basis of opportunity identification: entrepreneurial alertness. Small Business Economics. 2001;16:95-111.

75. Miller J, Hackley SA. Electrophysiological evidence for temporal overlap among contingent mental processes. J Exp Psychol Gen. 1992;121: 195-209.

76. Smid HGOM, Mulder G, Mulder LJM. The continuous flow model revisited: perceptual and central motor aspects. In: Johnson R, Parasuraman R, Rohrbaugh JW, editors. Current Trends in EventRelated Potential Research (EEG Supplement 40). Amsterdam, The Netherlands: Elsevier; 1987.

77. Smid HGOM, Lamain W, Hogeboom MM, Mulder G, Mulder LJM. Psychophysiological evidence for continuous information transmission between visual search and response processes. J Exp Psychol Hum Percept Perform. 1991;17:696-714.

78. Smid HG, Mulder G, Mulder LJ, Brands GJ. A psychophysiological study of the use of partial information in stimulus-response translation. J Exp Psychol Hum Percept Perform. 1992;18:1101-1119.

79. Smid HG, Böcker KB, Van Touw DA, Mulder G, Brunia CH. A psychophysiological investigation of the selection and the use of partial stimulus information in response choice. J Exp Psychol Hum Percept Perform. 1996;22:3-24.

80. Shane S, Venkataraman S. The promise of entrepreneurship as a field of research. Acad Manage Rev. 2000;25:217-226.

81. Baron RA. Opportunity recognition as pattern recognition: how entrepreneurs "connect the dots" to identify new business opportunities. Academy of Management Perspectives. 2006;20:104-119.

82. Anderson KJ, Revelle W. The interactive effects of caffeine, impulsivity, and task demands on a visual search task. Pers Individ Dif. 1983;4: 127-134.

83. Dickman S. Impulsivity and perception: individual differences in the processing of the local and global dimensions of stimuli. J Pers Soc Psychol. 1985;48:133-149.

84. Dickman S, Meyer DE. Impulsivity and speed-accuracy tradeoffs in information processing. J Pers Soc Psychol. 1988;54:274-290.

85. Eysenck HJ, Eysenck MW. Personality and Individual Differences: A Natural Science Approach. New York, NY: Plenum Press; 1985.

86. Eysenck HJ, Levey A. Conditioning, introversion-extraversion and the strength of the nervous system. In: Nebylitsyn VD, Gray JA, editors. Biological Bases of Individual Behavior. London, UK: Academic Press; 1972.

87. Loo R. Role of primary personality factors in the perception of traffic signs and driver violations and accidents. Accident Analysis and Prevention. 1979;11:125-127.

88. Revelle W, Humphreys MS, Simon L, Gilliland K. The interactive effect of personality, time of day, and caffeine: a test of the arousal model. J Exp Psychol Gen. 1980;109:1-31.

89. Folk CL, Remington RW, Johnston JC. Involuntary covert orienting is contingent on attentional control settings. J Exp Psychol Hum Percept Perform. 1992;18:1030-1044.

90. Kan IP, Thompson-Schill SL. Selection from perceptual and conceptual representations. Cogn Affect Behav Neurosci. 2004;4:466-482.

91. Bingham CB, Eisenhardt KM. Rational heuristics: the 'simple rules' that strategists learn from process experience. Strategic Management Journal. 2011;32:1437-1464.

92. Pashler H, Johnston JC, Ruthruff E. Attention and performance. Annu Rev Psychol. 2001;52:629-651.

93. Serences JT, Shomstein S, Leber AB, Golay X, Egeth HE, Yantis S. Coordination of voluntary and stimulus-driven attentional control in human cortex. Psychol Sci. 2005;16:114-122.

94. Itti L, Koch C. Computational modelling of visual attention. Nat Rev Neurosci. 2001;2:194-203.

95. Theeuwes J. Exogenous and endogenous control of attention: the effect of visual onsets and offsets. Percept Psychophys. 1991;49:83-90.
96. Theeuwes J. Perceptual selectivity for color and form. Percept Psychophys. 1992;51:599-606.

97. Folstein JR, Van Petten C. Influence of cognitive control and mismatch on the N2 component of the ERP: a review. Psychophysiology. 2008;45: 152-170.

98. Yeung N, Botvinick MM, Cohen JD. The neural basis of error detection: conflict monitoring and the error-related negativity. Psychol Rev. 2004;111:931-959.

99. Szucs D, Soltesz F, Bryce D, Whitebread D. Real-time tracking of motor response activation and response competition in a Stroop task in young children: a lateralized readiness potential study. $J \operatorname{Cogn}$ Neurosci. 2009;11:2195-2206.

100. Mager R, Meuth SG, Krauchi K, Schmidlin M, Muller-Spahn F, Falkenstein M. Mismatch and conflict: neurophysiological and behavioral evidence for conflict priming. J Cogn Neurosci. 2009;21: 2185-2194.

101. Szucs D, Soltész F. Stimulus and response conflict in the color-word Stroop task: a combined electro-myography and event-related potential study. Brain Res. 2010;1325:63-76.

102. Szucs D, Soltész F. Functional definition of the N450 event-related brain potential marker of conflict processing: a numerical Stroop study. BMC Neurosci. 2012;13:35.

103. Sarasvathy SD. Causation and effectuation: toward a theoretical shift from economic inevitability to entrepreneurial contingency. Academy of Management Review. 2001;26:243-263.

104. West WC, Holcomb PJ. Imaginal, semantic, and surface-level processing of concrete and abstract words: an electrophysiological investigation. J Cogn Neurosci. 2000;12:1024-1037.

105. Qiu J, Li H, Liu Q, Zhang Q. Brain mechanisms underlying visual perception and visual mental imagery of Chinese pseudo-characters: an ERP study. Brain Res. 2007;1184:202-209.

106. Belardinelli MO, Palmiero M, Sestieri C, et al. An fMRI investigation on image generation in different sensory modalities: the influence of vividness. Acta Psychol (Amst). 2009;132:190-200.

107. Metzler MP. Action, imagery and the N450. Presented at the 33rd annual meeting of the Cognitive Science Society, Boston, MA, July 20 to Saturday July 23, 2011. Available from: http://palm. mindmodeling.org/cogsci2011/papers/0722/paper0722.pdf. Accessed August 8, 2013.

108. Gallivan JP, McLean DA, Smith FW, Culham JC. Decoding effector-dependent and effector-independent movement intentions from human parieto-frontal brain activity. $J$ Neurosci. 2011;31: 17149-17168.

109. Farb NA, Segal ZV, Anderson AK. Attentional modulation of primary interoceptive and exteroceptive cortices. Cereb Cortex. 2013;23: 114-126.

110. FitzGerald TH, Seymour B, Dolan RJ. The role of human orbitofrontal cortex in value comparison for incommensurable objects. J Neurosci. 2009;29:8388-8395.

111. Bar M, Kassam KS, Ghuman AS, et al. Top-down facilitation of visual recognition. Proc Natl Acad Sci U S A. 2006;103:449-454.

112. Sehatpour P, Molholm S, Schwartz TH, et al. A human intracranial study of long-range oscillatory coherence across a frontal-occipitalhippocampal brain network during visual object processing. Proc Natl Acad Sci U S A. 2008;105:4399-4404.

113. Baker SC, Rogers RD, Owen AM, et al. Neural systems engaged by planning: a PET study of the Tower of London task. Neuropsychologia. 1996;34:515-526.

114. Lumpkin GT, Dess GG. Clarifying the entrepreneurial orientation construct and linking it to performance. Academy of Management Review. 1996;21:135-172.

115. Baron RA, Markman GD. Beyond social capital: the role of entrepreneurs' social competence in their financial success. Journal of Business Venturing. 2003;18:41-60.

116. Hisrich R, Langan-Fox J, Grant S. Entrepreneurship research and practice: a call to action for psychology. Am Psychol. 2007;62:575-589. 
117. Keh HT, Foo MD, Lim BC. Opportunity evaluation under risky conditions: the cognitive processes of entrepreneurs. Entrepreneurship Theory and Practice Journal. 2002;27:125-148.

118. Simon M, Houghton SM, Aquino K. Cognitive biases, risk perception, and venture formation: how individuals decide to start companies. Journal of Business Venturing. 1999;15:113-134.
119. Baron RA. Cognitive mechanisms in entrepreneurship: why and when entrepreneurs think differently than other people. Journal of Business Venturing. 1998;13:275-294.

120. Kahneman D. Thinking, Fast and Slow. Harlow, UK: Penguin Books; 2011.

\section{Publish your work in this journal}

Neuroscience and Neuroeconomics is an international, peer-reviewed, open access journal focusing on the identification of brain structures and measurement of neural activity related to behavior, behavioral predictions, and decision making in health and disease. The manuscrip management system is completely online and includes a very quick and fair peer-review system. Visit http://www.dovepress.com/testimonials. php to read real quotes from published authors. 